\title{
Exploration of the new mode of communication between institutions of higher learning and primary and secondary schools which is based on the volunteering and social practice of College Students
}

\author{
Yu Feng \\ School of Electrical \&Electronic Engineering, North China Electric Power University, Beijing, 102206, \\ China. \\ fengyuhm@163.com
}

\begin{abstract}
With the development of the social economy, people's needs for basic education have been becoming diversified and comprehensive. Meanwhile, the kind of phenomenon that groups of students couldn't adapt to the changes in the transition phase between basic education and higher education raised social concern over and over again. In this new situation, more communication and exchanges are necessary for the primary and secondary schools and institutions of higher learning, to promote students' growth. Based on the analysis of the present main cooperation mode between colleges and universities and elementary and secondary schools as well as their construction background and operation mode, this article proposes a new type communication model which depends on college students' social work and volunteer activities.
\end{abstract}

Keywords: communication mode; colleges and universities; elementary and secondary schools; university students; social practice; voluntary activities.

\section{Introduction}

With the rapid development of the urbanization all over the country, the needs of basic education are increasing dramatically. In this context, in the purpose of improving education levels and promoting the rational distribution of education resources, our country has come up with $<$ The national medium and long-term education reform and development plan outline (2010-2020)> which contains a series of educational reform measures.

\section{Background of the cooperation and exchange between colleges and primary and secondary schools}

\subsection{The masses put forward higher requirements for basic education}

Nowadays, with the improvement of living standards, people invest greater attention and energy for children's education. In the basic education stage, the parents' expectations for school are no longer limited to high scores on the exam paper, but wants that their kids get trained in handling ability, arts, technological innovation as well as other aspects. The elementary education stage, is an important stage of human development. A number of important personal qualities, like individual ways of thinking, study habits are formed at this stage. However, due to large population size and low level of economic development, China' basic education stressed only "rote learning" for a long time, ignoring the cultivation of student's creativity. Consequently, groups of students who has only poor inactive thinking ways and bad creativity graduated year by year. However, in recent years, with China's rapid economic development, investments in basic education from the government and family have increased significantly, meanwhile, people put forward higher requirements for basic education. \subsection{Parents and students lack understanding about University life and even have} misunderstandings.

With regard to the way of learning and lifestyle in college, there is a big misunderstanding in Primary and middle school students group and even their parents. In order to stimulate students to study in high school, some parents and teachers instill in students wrong idea like "After you enter the college, you get free." In the basic education stage, some students' study life is always under the 
supervision of parents and teachers, which means they don't have the self-directed learning ability. Parents and teachers just tell their children and students learning is important but forget to inspire their learning fun. As a result of this mode of education, when the group of children enter the college, they don't know what specialty they like and what specialty they fit, and gradually lose interest for study. At last, even if some of them realize they are here to get knowledge and learn a living skill, they are about to put more efforts to catch up with others. Besides, due to lack of understanding of university life, quite a few students do not like, and are not suitable for their chosen professional, causing setbacks and even inducing psychological problems. Therefore, smooth and efficient ways to improve students' transition from elementary to higher education study and life become very important.

\subsection{Apparent difference in pattern of developing talents between basic and higher education stage}

There is a contradictory phenomenon of education in China: In the basic education stage, the first goal of education is to get the students know all kinds of the so-called basic knowledge involving Chinese, Mathematics, foreign language, geography, history, biology and so on, and to remember them, students practice over and over again while creativity consciousness and handing skills are put behind. However, in higher education stage, innovation and manipulative ability become an important standard to judge whether a student is excellent. The phenomenon not only brings to the students' adaptation problems, but also lower the quality of talent cultivation, resulting in substantial waste of social resources. Therefore, it is imperative to strengthen communication between the universities and primary and secondary schools.

\section{The main current models of exchange between institution of higher learning and primary and secondary schools}

In response to these circumstances, the Ministry of education and local education Committee issued a series of policies to improve the present situation of poor connection between basic education and higher education. In Beijing, for example, cooperation and exchange between institution of higher education and primary and secondary schools are mainly in the form of the following three ways:

\subsection{Institutions of higher education and primary and secondary school cooperate in running schools [1]}

The mode of cooperating in running schools is quiet similar to affiliated school, but not all the same. An affiliated school is an educational institution that operates independently, but also has a formal collaborative agreement with another, usually larger institution that may have some level of control or influence over its academic policies, standards or programs. In china, affiliated schools can be traced back more than 100 years ago, the high school affiliated to Beijing Normal University. Here,the two sides are no longer a dependency relationship, but more likely is a partnership.

In this mode, although universities and schools have different backgrounds, areas of cooperation, but they have one thing in common, they all want to improve teaching quality and research level on both sides through cooperative education, and finally achieve a win-win goal.

From Beijing's current situation, starting in 2014, Beijing Municipal Education Commission launched " institution of higher education support the affiliated schools development projects", vigorously promoting the institutions of higher education and primary and secondary schools to build a close relationship. In support of this project, many universities including North China electric power University, capital University of Economics and business and others have achieved cooperation with middle and primary school, which means they have their "affiliated schools".

Through such kind of cooperation, the universities and the primary and secondary school enhance the communication between each other,achieve internal quality education resources sharing and finally promote their own progress. 


\subsection{Junior Open experiment project in Beijing City}

Junior Open experiment project in Beijing City is a project carried out by Beijing Municipal Education Commission from 2015. In the project, through using network management service platform, nearly 90, 000 students of junior one all over Beijing city have the opportunity to choose lessons provided by universities, research institutions, social organizations, enterprises, and other institutions according to their preferences. For convenience, not only can students choose lessons by themselves, group booking is also included. Besides, the contents of the project cover nature and environment, health and safety, structural and mechanical, energy and materials, electronics and control and other fields. Students participating in activities at a time can come from different areas, different schools, and different year classes. The activities are mainly arranged at after-school time, weekends, holidays, and so on.

\subsection{Participation in primary schools' by colleges and universities}

The core of the project is to use the advanced educational resources from institutions of higher learning and social organizations. With their help, primary schools can get improved in aesthetic and art education.

\section{Analysis and evaluation of the three cooperation and exchange modes above}

First of all, with regard to the form of constructing schools together, it remains many problems unsolved despite of its obvious advantages. According to the statistics released by the official website of the Ministry of education [2], by the time of May 30, 2016 there are 2560 universities (including 275 independent colleges) in china, while the number of general high school, middle school and primary school is respectively 13, 200, 52, 400 and 190, 500. Obviously, the gap between the numbers greatly limits the promotion and implementation of the mode.

Secondly, the "Junior Open experiment project" model also has many problems. Beijing, as the country's political, cultural and economic center, numerous colleges and universities gather here and its education investment is very large, but such advantages are not owned by other cities. Therefore, this model is difficult to get a promotion in areas without rich educational resources and developed economy. In other words, Beijing's Junior Open experiment project doesn't have great reference value to other areas.

Finally, it concludes China's education needs a new communication and exchange mode between colleges and primary and secondary schools which has lower economic costs and more covenience.

\section{The mode of exchange based on volunteering and social practice of college students}

\subsection{Introduction of the mode}

Volunteering is generally considered an altruistic activity where an individual or group provides services for no financial gain to benefit another person, group or organization [3]. Besides, social practice is defined as activities done to participate in social activities.

Start from 1993 when Communist Youth League Central Committee initiate "China Youth Volunteers action", colleges and universities all over the country established youth volunteers' organization, college students gradually become the main force involved in volunteer activities.

College students, as principal talent of a country, have good cultural qualities, high level of knowledge. If we bring their social practice and charity voluntary activities into the communication and exchange activity, this can greatly enhance the depth and breadth of institutions of higher learning and primary and secondary school exchanges and cooperation [4].

In simple terms, the new mode is that college students teach middle and primary school students, and its detailed explanation is as follows.

On a small scale, such as a college, on the basis of community organizations, youth league branch or other students groups, college students who has the same ideas gather together. Then, on the basis of the knowledge they learned in college class, they determine the theme of the course. Afterwards, in the progress of prepare the course, according to their actual situation, they can add knowledge such as 
how to make a small invention, a small handmade or some frontier trends about their own specialty. Finally, after contacting with someone, under some kind requirements of safety, they enter the primary and secondary schools, provide the students their well-prepared course.

On a larger scale, different colleges and universities within an area have the potential to form a union, then the related activities could combine each other. Though communication and contact with surrounding primary and secondary schools, places and time for different courses could be arranged organized, and at last, it forms a comprehensive, knowledgeable curriculum system. For the college students, they have the ability to do such activities through volunteer activities, social activities, community activities at a small economic cost. For the students in primary and secondary schools, they could learn more about the specialty, the college lifestyle, even learning experience, which not only enriches their knowledge, expandes their horizons, but also reduces their misunderstandings about college lifestyle and specialties. In all, such activities have great social benefits.

\subsection{Feasibility analysis}

First of all, college students have the ability and a need to do such activities. Nowadays, social practice and volunteering have been parts of many college students campus life. Apart from the factor that participation in such activities has been involved in students' comprehensive quality evaluation system, lots students are encouraged to do these because they feel happiness in the progress of devoting oneself. According to a survey report ${ }^{[5]}, 72.84 \%$ of college student volunteers think they participate in such activities because "helping people make them very happy, and play their role in the society". The other hand, one investigation report of Beijing University shows that having no channels is the main reason why some students at the school don't participate in voluntary activities. Thus, in such a mode described before, which provides college students with more opportunities, college students have more chance to fulfill their potential.

On top of the needs of college students, they are sure to have the ability to establish them well. On the one hand, college students, they have experienced twelve years or more study life and the university entrance examination, they have more experience and know better how to overcome the difficulties in learning life. On the other hand, "small class" itself is not a normal classroom teaching, but more like a sharing activity focusing on exchanging and showing, thus, there isn't a high requirement of teaching ability for speakers. In addition, after years of accumulated study, the majority of college students have good presentation skills.

Besides,Primary and secondary schools take a positive attitude to such activitiesThe kind activity is essentially in order to deepen exchanges and communication between institutions of high education and primary and secondary schools, enhance students ' awareness of all aspects of the University, expand students ' horizons, in all, such activities meet the needs of primary and secondary schools and their students.

\subsection{Advantage analysis}

In such kind activities, college students, act as communicator between institutions of higher learning and primary and secondary schools, have the following advantages:

First, it meets the needs of college students and the primary and secondary schools;

Second, it provides Middle and primary school students with the first-hand information about college lifestyle and so on;

Third, it diversifies the value realization ways of college students;

Fourth, it has a lower social costs.

\section{Conclusion}

In conclusion, in view of such advantages described as above, the new mode of communication between institutions of higher learning and primary and secondary schools which is based on the volunteering and social practice of College Students provide a choice and reference for the government and officer to make a better decision, and at, improve the educational level of china. 


\section{References}

[1] Xing Qiu. Analysis of cooperation in running schools between Primary and secondary schools and institutions of higher learning. Education Review. Vol. (2008) No. 4, p. 44.

[2] Information on:http://www.moe.edu.cn/srcsite/A03/s180/moe_633/201607/t20160706_270976.html

[3] Wilson J. Volunteering. Annual Review of Sociology. Vol. (2000) No.2, p. 215.

[4] Wenxin Xu, Wuyi Li, Yan Li. Present situation and development of Chinese youth volunteering. China Youth Study. Vol. (1996) No. 2, p. 14-15.

[5] Yanze He, Jiang Zhu. Research on the implementation of voluntary activities of students in China Medicine University. Time Education. Vol (2012) No. 23, p. 90. 